\title{
Patient selection in ambulatory anesthesia - An evidence-based review: part I
}

\section{[La sélection des patients en anesthésie ambulatoire - Une revue factuelle : partie I]}

Gregory L. Bryson FrCPC MSc, ${ }^{*}$ Frances Chung MB FRCPC, $†$ Barry A. Finegan MB FRCPC, Z Zeev Friedman MD, $\$$ Donald R. Miller MD FRCPC, * Janet van Vlymen MD FRCPC, If Robin G. Cox MB BS FRCA FRCPC, Marie-Josée Crowe MD FRCP, ${ }^{*}$ John Fuller MD FRCPC,†† Cynthia Henderson MD FRCPC, $\ddagger$ for the Canadian Ambulatory Anesthesia Research and Education (CAARE) Group

Purpose: To identify and characterize the evidence supporting decisions made in the care of patients with selected medical conditions undergoing ambulatory anesthesia and surgery. Conditions highlighted in this review include: the elderly, heart transplantation, hyper-reactive airway disease, coronary artery disease, and obstructive sleep apnea.

Source: A structured search of MEDLINE (1966-2003) was performed using keywords for ambulatory surgery and patient condition. Selected articles were assigned a level of evidence using Centre for Evidence Based Medicine (CEBM) criteria. Recommendations were also graded using CEBM criteria.

Principal findings: The elderly may safely undergo ambulatory surgery but are at increased risk for hemodynamic variation in the operating room. The heart transplant recipient is at increased risk of coronary artery disease and renal insufficiency and should undergo careful preoperative evaluation. The patient with reactive airway disease is at increased risk of minor respiratory complications and should be encouraged to quit smoking. The patient with coronary artery disease and recent myocardial infarction may undergo ambulatory surgery without stress testing if functional capacity is adequate. The patient with obstructive sleep apnea is at increased risk of difficult tracheal intubation but the likelihood of airway obstruction and apnea following ambulatory surgery is unknown.

Conclusion: Ambulatory anesthesia is infrequently associated with adverse outcomes, however, knowledge regarding specific patient conditions is of generally low quality. Few prospective trials are available to guide management decisions.
Objectif : Identifier et caractériser la preuve à l'appui des décisions prises sur les soins à donner aux patients qui présentent des pathologies médicales ciblées et qui subissent une anesthésie en chirurgie ambulatoire. Les situations sélectionnées dans cette revue comprennent : la vieillesse, la transplantation cardiaque, l'affection respiratoire hyper-réactionnelle, la coronaropathie et l'apnée obstructive du sommeil.

Source : Une recherche structurée dans MEDLINE (1966-2003) a été réalisée selon les mots clés pour la chirurgie ambulatoire et l'état du patient. Les articles choisis ont été cotés selon le niveau de preuve des critères du Centre for Evidence Based Medicine (CEBM). Les recommandations ont aussi été graduées selon les critères du CEBM.

Constatations principales : Les personnes âgées peuvent subir une opération ambulatoire en toute sécurité, mais sont plus à risque de variation hémodynamique en salle d'opération. Les greffés cardiaques sont plus à risque de coronaropathie et d'insuffisance rénale et doivent avoir une évaluation préopératoire minutieuse. Les cas d'affection respiratoire réactionnelle sont plus à risque de complications respiratoires mineures et doivent être encouragés à cesser de fumer. Le patient atteint de coronaropathie, victime récente d'infarctus myocardique, peut être vu en chirurgie ambulatoire sans épreuve d'effort si la capacité fonctionnelle est adéquate. En cas d'apnée obstructive du sommeil, il y a plus de risque de difficulté d'intubation trachéale, mais la possibilité d'obstruction des voies aériennes et d'apnée à la suite d'une opération ambulatoire n'est pas connue.

Conclusion : L'anesthésie ambulatoire n'est pas souvent associée à des complications, même si la connaissance de pathologies spécifiques est peu développée en général. Il existe peu d'études prospectives permettant de guider les décisions thérapeutiques.

From the Department of Anesthesiology, The Ottawa Hospital, ${ }^{*}$ Ottawa, Ontario; Department of Anesthesia, Toronto Western Hospital, $\dagger$ Toronto, Ontario; Department of Anesthesiology and Pain Medicine, University of Alberta, $\ddagger$ Edmonton, Alberta; Department of Anesthesia, Mount Sinai Hospital, $\mathbb{S}$ Toronto, Ontario; Department of Anesthesiology, Kingston General Hospital, $\mathbb{I}$ Kingston, Ontario; Department of Anesthesia, Alberta Children's Hospital, Calgary, Alberta; Département d'Anesthésiologie, Hôpital Ste-Justine, ** Montréal, Québec; Department of Anesthesia and Perioperative Care, St. Joseph's Health Care, †† London, Ontario; and Department of Anesthesia, Vancouver General Hospital, $\ddagger \ddagger$ Vancouver, British Columbia, Canada. Address correspondence to: Dr. Gregory L Bryson, Department of Anesthesiology, Head, Pre-Admission Units, The Ottawa Hospital, 1053 Carling Avenue, Ottawa, Ontario KIY 4E9, Canada. Phone: 613-761-4169; Fax: 613-761-5209; E-mail: glbryson@ottawahospital.on.ca Meeting facilities were sponsored by Purdue Pharma. Accepted for publication February 2, 2004. Revision accepted May 14, 2004. 


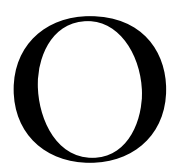

VER 1.8 million Canadians undergo ambulatory surgery annually. ${ }^{1}$ An American study of outcomes in the 30 days following ambulatory surgery documented only four deaths, two from myocardial infarction (MI) and two from motor vehicle accidents in 38,598 patients. $^{2}$ The risk of major morbidity in the same time period following ambulatory surgery was only one in 1,455 . The relative safety of ambulatory surgery has led to an expansion of ambulatory care to an increasingly elderly and frail patient population. Shrinking hospital resources have similarly increased the complexity of procedures offered on an outpatient basis. Determining the appropriateness of a given surgical procedure in an individual patient asks the clinician to strike a balance between patient safety and the practicalities of resource use.

In June 2002 the Canadian Ambulatory Anesthesia Research and Education (CAARE) Group, a panel of anesthesiologists from across Canada, met to evaluate eligibility criteria for ambulatory surgery in Canada. It became apparent that a comprehensive list of patients and procedures suitable for ambulatory care would be difficult, if not impossible, to define. A different approach was required.

\section{Methods}

Panelists chosen were selected from academic and non-academic centres based on their interest in ambulatory anesthesia and perioperative medicine. All regions of Canada were represented to capture a diversity of practice styles. Both adult and pediatric anesthesiologists were included. Following the 2002 meeting, panelists were assigned a clinical scenario based on their areas of expertise. The scenarios combined a relatively controversial patient population with a common ambulatory surgical procedure. A series of "answerable" questions were designed to frame relevant management issues. Structured literature searches were conducted by combining keywords for selected patient conditions and ambulatory surgery. The search terms used may be found in Appendix I. Subsequent unstructured searches supplemented by bibliography review were conducted to focus the literature on the questions posed.

The panelist assigned each topic and a reviewer with expertise in evidence-based medicine and research design (G.L.B.) reviewed all identified publications relevant to a given scenario. The panel reconvened in June 2003 to identify and characterize the level of evidence concerning the questions posed in each scenario. Publications were reviewed and assigned a level of evidence using the criteria of the
Centre for Evidence Based Medicine (CEBM). ${ }^{3}$ The level of evidence for each publication was assigned by consensus following review of the publication by group as a whole. Recommended answers to the questions were then supported using the highest level of evidence available. Retrospective studies were excluded if prospective research was available. Observational research was rejected if prospective randomized trials answered the question posed. With best evidence identified, the CEBM guidelines were used to characterize the strength of the knowledge supporting each recommendation. A summary of the levels of evidence and grades of recommendation may be found in Appendices II and III. A list of the individual articles cited and their level of evidence (Appendix A) is available as Additional Material at www.cja-jca.org.

The authors did not attempt to perform a statistical pooling of the findings as found with a meta-analysis. The goal was to provide a narrative review of management controversies and clearly describe the research available to support treatment decisions. The conditions and questions selected neither represent all issues faced in the management of a given condition nor do they provide a complete picture of the controversies in ambulatory anesthesia today. It is likely that this exercise will raise more questions than it answers. It is hoped that critical review will improve our understanding of these issues and highlight the strength and weakness in ambulatory care research. The methods used may provide a framework for evaluating other questions faced by anesthesiologists in their own practices.

\section{The elderly}

Scenario

A 70-yr-old male is scheduled for transurethral resection of a bladder tumour (TURBT). He has a ten-year history of hypertension, now treated with lisinopril. On physical examination his blood pressure is $150 / 90$ $\mathrm{mmHg}$, heart rate 72 beats. $\mathrm{min}^{-1}$ and heart sounds are normal. The surgeon would like to perform surgery on an outpatient basis.

\section{Discussion}

The elderly population is the fastest growing segment of ambulatory surgical patients. Improvements in anesthetic and surgical techniques allow patients to return to their regular environment and lifestyle with minimal disruption. This is particularly important among the elderly who have decreased ability to adapt to new situations. 


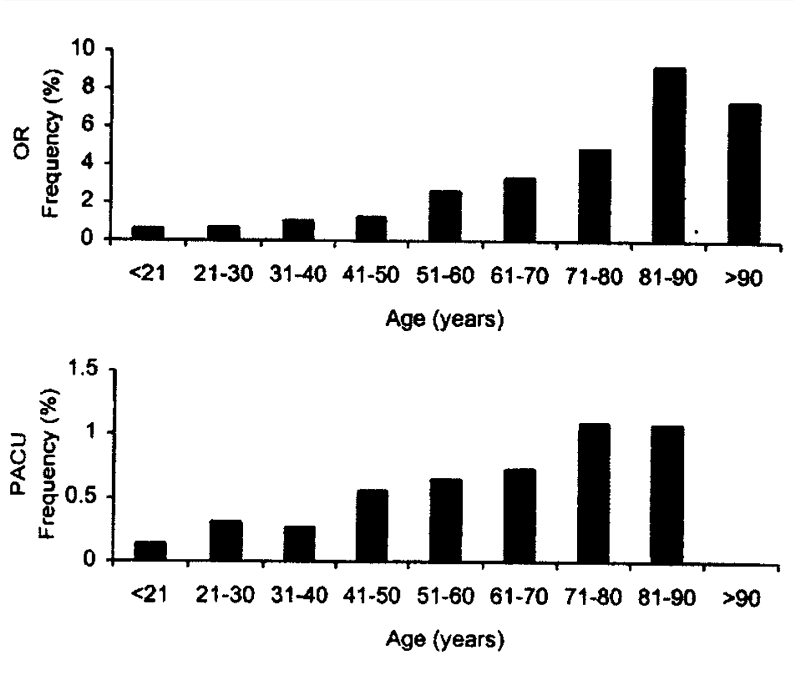

FIGURE Adverse events in the operating room $(\mathrm{OR})$ and postanesthesia care unit $(\mathrm{PACU})$ with increasing age ${ }^{6}$

Is age an independent risk factor for adverse perioperative events?

Evidence evaluating the influence of age on perioperative outcome has been contradictory. A prospective cohort of 15,172 patients undergoing ambulatory surgery found that age did not predict unanticipated admission. ${ }^{4}$ ASA classification $\geq$ III, emergency surgery, and intraoperative tachycardia predicted postoperative adverse outcomes in a much smaller study of patients $\geq 70 \mathrm{yr}$ of age undergoing noncardiac surgery. ${ }^{5}$ On the other hand, a cohort study including 4,786 outpatients identified an association between $>65 \mathrm{yr}$ of age and an increased risk of intraoperative adverse events [adjusted odds ratio (OR) $1.42,95 \%$ confidence interval (CI) 1.00-2.00]. ${ }^{6}$ The majority of these events were related to changes in hemodynamic variables and increased in proportion with age (Figure). Interestingly these same elderly patients were far less likely to suffer adverse events postoperatively (OR $0.4,95 \%$ CI $0.3-0.6$ ). Fleisher identified age > 85 , longer operating room stay, cardiac diseases, peripheral vascular diseases, cerebrovascular diseases, malignancy, HIV positive status and general anesthesia as independent predictors of hospitalization and death following outpatient surgery. ${ }^{7}$ The influence of age on perioperative outcome is inconsistent among studies but may be important at the extremes of age (grade D).

\section{Does hypertension place the patient at additional peri- operative risk? \\ A variety of pre-existing medical conditions increase the risk of perioperative complications in ambulatory surgery}

TABLE I Association between pre-existing medical conditions and adverse outcomes ${ }^{8}$

\begin{tabular}{ll}
\hline Medical condition & $\begin{array}{l}\text { Associated adverse outcome } \\
\text { Congestive heart failure } \\
12 \% \text { prolongation of postoperative } \\
\text { stay }\end{array}$ \\
Hypertension & $\begin{array}{l}2 \text {-fold increase in the risk of } \\
\text { intraoperative cardiovascular events }\end{array}$ \\
Asthma & $\begin{array}{l}5 \text {-fold increase in the risk of } \\
\text { postoperative respiratory events } \\
\text { 4-fold increase in the risk of } \\
\text { postoperative respiratory events } \\
\text { Smoking }\end{array}$ \\
-fold increase in risk of intraoperative \\
and postoperative respiratory events \\
8-fold increase in the risk of \\
GE reflux
\end{tabular}

$\mathrm{GE}=$ gastroesophageal

(Table I). ${ }^{8}$ Patients with hypertension suffered an increase in cardiovascular (OR 2.47, 95\% CI 1.45-4.19) and all intraoperative events (OR 2.21, 95\% CI $1.37-3.58$ ) in the prospective cohort of 17,368 ambulatory patients described above. ${ }^{9}$ Hypertension did not, however, predict adverse postoperative events in a smaller cohort study of elderly patients. ${ }^{5}$ As with age, the influence of hypertension is inconsistent and primarily affects intraoperative hemodynamics (grade D).

What is the risk of doing a TURBT as an outpatient? $4.9 \%$ of cystoscopy and TURBT procedures resulted in unanticipated hospital admissions compared with $1.42 \%$ of all patients studied in Fortier's prospective cohort. ${ }^{4}$ The 30 -day readmission rate for patients undergoing TURBT was $5.7 \%$, much higher than the $1.1 \%$ readmission rate noted in other outpatient surgical procedures $(P<0.0001) .{ }^{10}$ Patients undergoing TURBT represent a unique risk group for unplanned admission on the day of surgery and readmission following discharge (grade A).

Does preoperative laboratory testing influence outcome? Laboratory testing is frequently ordered in the preoperative evaluation of the elderly but may be of little value. Abnormalities identified on preoperative complete blood count and electrolytes, though common, did not predict outcome. ${ }^{11}$ Routine medical testing before cataract surgery was found to have no influence on the likelihood of postoperative events ${ }^{12}$ but it is unclear if this may be extrapolated to other procedures. Routine laboratory evaluation, even in the elderly, may be of little practical value (grade B). 


\section{Conclusion - the elderly}

The influence of age on perioperative outcome may be important at the extremes of age ( $>85 \mathrm{yr}$ old). Both age and hypertension predispose to changes in intraoperative hemodynamics but do not lead to adverse outcome. Patients undergoing TURBT are at $5 \%$ risk of unanticipated admission or readmission following an outpatient procedure. A 70-yr-old patient with hypertension can be safely operated as an ambulatory surgical patient. The patient, anesthesiologist, and surgeon should be aware of the increased risk of postoperative admission and plan accordingly.

\section{Heart transplantation}

Scenario

A 56-yr-old, 98-kg man who received an orthotopic heart transplant six months previously is referred for laparoscopic cholecystectomy for biliary colic in a community hospital. His medical history is significant for hypertension. Current medications include diltiazem, metformin, prednisone, cyclosporine and azathioprine. He denies dyspnea and syncope and states he has excellent exercise tolerance since his transplant procedure. $\mathrm{He}$ is afebrile and clinical examination is unremarkable.

\section{Discussion}

Approximately 2,000 heart transplants are performed annually in North America, with one- and three-year survival rates of $84 \%$ and $77 \%$, respectively. ${ }^{13}$ Heart transplant patients have a markedly increased incidence of pancreaticobilary disease when compared to the general population [relative risk (RR) 17.4, 95\% CI 9.2-32.7] making the scenario presented above relatively common. ${ }^{14}$

Preoperative evaluation of the transplant recipient must identify complications specific to heart transplantation, including graft rejection, cardiac allograft vasculopathy, and ventricular diastolic dysfunction. ${ }^{15}$ Infection is a constant threat with any immunosupressed patient and symptoms or signs of infection may be few. A minor rise in body temperature should be investigated and the intended surgical procedure deferred. ${ }^{16}$ Careful preoperative assessment, well in advance of the scheduled surgery, should allow consultation with the transplant specialist caring for the patient. A thorough assessment on the day of surgery is required to confirm that the status of the patient has not changed since the initial preoperative evaluation.

\section{Is a preoperative troponin measurement useful?}

Acute graft rejection occurs most frequently at four to six weeks postoperatively, but may also occur months or even years later. Diagnosis is confirmed with an invasive endomyocardial biopsy. ${ }^{15}$ Measurement of tropinin I was assessed in a prospective cohort of 110 transplant recipients. ${ }^{17}$ Patients with persistently elevated levels of troponin I had a significantly increased risk for subsequent development of coronary artery disease (CAD; OR, 4.3; 95\% CI, 1.8-10.1) and graft failure (OR, 3.4; 95\% CI, 1.2-9.7). Regrettably, two cases of acute rejection were not reflected in elevations of either troponin $\mathrm{T}$ or I when assessed in a smaller subsequent cohort. ${ }^{18}$ At this point measurement of tropinin isoenzymes cannot be recommended as a preoperative screening test for acute rejection (grade D).

\section{Do transplant recipients require preoperative cardiac testing?}

Sympathetic denervation of the transplanted heart renders the recipient unable to experience angina in the presence of myocardial ischemia. ${ }^{16}$ As such, patient history cannot be relied upon to detect significant coronary disease. Cardiac allograft vasculopathy, a form of premature $\mathrm{CAD}$, occurs in $45 \%$ of grafted hearts by one year. ${ }^{19}$ As coronary disease in transplant recipients is diffuse and predominantly in small vessels the use of dobutamine stress echocardiography (DSE) has been advocated as a less invasive alternative to angiography. DSE was $92 \%$ sensitive and $73 \%$ specific in identifying coronary stenosis occurring in $70 \%$ of patients five years post-transplant. ${ }^{20}$ Preoperative review of an electrocardiography to detect evidence of infarction would seem reasonable. In keeping with published guidelines, ${ }^{21}$ our patient's excellent functional capacity suggests a DSE would not be required (grade B).

Is a preoperative evaluation of renal function indicated in patients who are taking calcineurin inbibitors?

The calcineurin inhibitors, cyclosporine and tacrolimus, are both associated with time-dependent development of renal dysfunction. A retrospective series of 123 pediatric heart transplant recipients revealed significant reductions in glomerular filtration rate in 38\% of patients and end-stage renal failure in $3 \%{ }^{22}$ A review of 219 patients who had undergone lung or heart-lung transplantation identified a steady decline in renal function resulting in a doubling of creatinine in $53 \%$ by five years and a $7.3 \%$ incidence of end-stage renal failure. ${ }^{23}$ A case-control study did not identify patient characteristics predicting renal failure but did note that $40 \%$ of heart transplant recipients died within one year of starting dialysis. ${ }^{24}$ Preoperative evaluation of renal function is appropriate given the prevalence of renal dysfunction in transplant recipients (grade $\mathrm{C}$ ). 
Does the method of anesthesia influence outcome?

The unique physiology of the transplanted heart must be considered in any anesthetic technique. Denervation results in a resting heart rate of 90 to 100 beats. $\mathrm{min}^{-1}$ and in the absence of an immediate cardiovascular response to intubation/pain/awareness. Drugs altering autonomic function such as atropine and neostigmine may have limited effects on heart rate, with responses being greater in patients in whom the graft has been present for some years. ${ }^{25}$ This biphasic response reflects possible reinnervation of the heart with time. ${ }^{26}$ Direct acting $B$ agonists (isoprenaline, norepinephrine and epinephrine) will have an exaggerated effect due to an increase in adrenoceptor density in the transplanted heart. Joshi et al., administered balanced general anesthesia to 11 cardiac transplant recipients undergoing laparoscopic cholecystectomy. ${ }^{27}$ Cardiac index and hemodynamics were unaltered by the establishment of a pneumoperitoneum and all patients recovered without adverse event. A series of 18 heart transplant recipients undergoing 32 noncardiac surgical procedures under general anesthesia, regional anesthesia, and monitored anesthesia care suffered no adverse events. ${ }^{28}$ There is a paucity of evidence suggesting that outcome in this patient population is influenced by the method of anesthesia (grade D).

\section{Is ambulatory surgery appropriate for this patient pop- ulation?}

Heart transplant recipients undergoing surgery for acute cholecystitis are poor candidates for outpatient surgery with $47 \%$ suffering postoperative morbidity in one recent series. ${ }^{29}$ Uncomplicated courses following laparoscopic cholecystectomy for biliary colic have been described in case series ${ }^{29,30}$ however only one patient in these studies was operated on an ambulatory basis. There is little published evidence supporting either the safety or harm of an ambulatory procedure (grade D).

\section{Conclusion - heart transplantation}

A systematic search of the literature revealed no extant data that specifically details selection criteria or outcome in heart transplant recipients subjected to outpatient surgery. In a stable patient with an orthotopic heart transplant laparoscopic cholecystectomy is not associated with cardiovascular complications and performing such surgery on an outpatient basis is an acceptable option.

\section{Hyper-reactive airway disease \\ Scenario}

A 56-yr-old female is scheduled for an ambulatory lumbar microdiscectomy. She has a history of chronic bron- chitis and smoking (40 pack/year). She functions well in daily life with occasional use of bronchodilators. One month ago, she was admitted to the emergency department for six hours because of an acute exacerbation. She was treated with bronchodilators, antibiotics and a one-week course of prednisone. She has had no cough or sputum production for two weeks and has returned to her normal physical activities.

\section{Discussion}

It is estimated that 14 million persons in the United States suffer from chronic obstructive pulmonary disease (COPD) and approximately the same number suffer from asthma. ${ }^{31}$ COPD and asthma are separate entities, asthma being a disease with reversible airflow obstruction, but in many cases it is impossible to differentiate between the two. Both these entities however usually share hyper-reactivity of the airways. ${ }^{32}$

\section{Are patients with COPD at increased risk for perioper- ative complications?}

There are numerous studies evaluating the influence of asthma and COPD on perioperative events following inpatient surgery. In a prospective cohort of over 160,000 patients, $1.5 \%$ of surgical patients developed postoperative pneumonia. A history of COPD doubled the risk (OR 1.72, 95\% CI 1.55-1.91) of postoperative pulmonary complications. ${ }^{33}$ Perioperative respiratory events were evaluated in a smaller cohort of 105 patients with relatively severe COPD, defined as a forced expiratory volume in one second (FEVI) $<50 \%$ predicted, who underwent major noncardiac surgery. Postoperative pulmonary complications occurred in $34 \%$ and pneumonia in $7 \% .{ }^{34}$ Pulmonary complications in asthmatics are more difficult to define. Bronchospasm developed in $2 \%$ of 706 previously diagnosed asthmatics undergoing surgery. ${ }^{35}$ A survey of Japanese patients with reactive airway disease showed a $20 \%$ incidence of postoperative bronchospasm. ${ }^{36}$

Literature specifically characterizing pulmonary risk following ambulatory procedures is very limited. In a recent prospective evaluation of pre-existing medical conditions in ambulatory surgery, patients with asthma (OR 4.61, 95\% CI 1.18-18.0) and smokers (OR 3.84, 95\% CI 1.11-13.3) were identified as having an increased risk for postoperative respiratory events. ${ }^{9}$ There was no significant association between respiratory disease and length of stay in recovery after ambulatory surgery. ${ }^{37}$ This may be an indication that these events were relatively minor. A four-centre Canadian study of 6,914 patients having ambulatory procedures found that patients with asthma (RR 7.2, $P<0.01)$ or COPD (RR 10.1, $P<0.01$ ) had an increased risk of 
perioperative lower airway events (e.g., bronchospasm) and a twofold increased risk of any operating room event. ${ }^{38}$ Patients suffering from reactive airway disease are at higher risk for ambulatory surgery perioperative complications, although these may usually be minor events (grade A).

\section{Should symptomatic patients undergo anesthesia and surgery?}

Asymptomatic patients with asthma have a very low frequency of complications, approaching that of the non-asthmatic population. ${ }^{35,36}$ However, those experiencing respiratory symptoms at the time of surgery faced a $50 \%$ incidence of postoperative respiratory complications compared with less than $2 \%$ of those without symptoms $(P=0.002)$. Respiratory complications dropped to $4.5 \%$ in those with symptoms within 30 days of surgery but remained at greater risk than asymptomatic controls $(P=0.002)^{35}$ (grade $\left.\mathrm{C}\right)$.

Does preoperative spirometry predict postoperative events? The role of pulmonary function tests as predictors of adverse outcomes is controversial. Patients with a FEVI $<40 \%$ of predicted values undergoing abdominal surgery were found to be at a significantly greater risk of bronchospasm (OR 6.9, 95\% CI 1.2-38.4) but were no more likely to require prolonged ventilation or intensive care unit (ICU) stays. ${ }^{39}$ Marked reductions in FEVI $(<0.75 \mathrm{~L})$ were predictive of pulmonary complications, ICU stay, and mortality in a cohort of selected patients undergoing abdominal surgery. ${ }^{34}$ Pulmonary function tests demonstrating forced expiratory volumes $<70 \%$ of predicted, identified those patients at risk of developing hypercarbia and acidosis during laparoscopic cholecystectomy. ${ }^{40}$ In contrast, spirometry was not predictive of pulmonary complications in an unselected group of patients undergoing abdominal surgery. ${ }^{41}$ An association between preoperative spirometry and postoperative complications was not identified in a retrospective cohort of patients with FEVI $<50 \% .{ }^{42}$ Studies evaluating preoperative pulmonary function testing before major surgery are inconclusive $e^{43}$ and generally lacking for the relatively minor ambulatory procedures. Preoperative spirometry cannot be recommended for patients without acute symptoms (grade D).

\section{Should smoking cessation be encouraged?}

A recent cohort study of 489 patients evaluated the influence of smoking on the incidence of perioperative complications following ambulatory surgery. ${ }^{44}$ Smokers experienced an increased risk of respiratory (OR 1.71, 95\% CI 1.03-2.84) and wound (OR 16.3, 95\% CI
1.58-175) complications. Patients who stopped smoking less than four weeks preoperatively suffered adverse events at a rate similar to current smokers. On the other hand, a randomized controlled trial of 120 patients undergoing joint arthroplasty demonstrated that smoking cessation begun six to eight weeks preoperatively yielded improvements in wound related complications. Only four patients (numbers-needed to-treat $4,95 \% \mathrm{CI}$ 2-8) need to cease smoking to prevent a single wound complication. ${ }^{45}$ Smoking cessation should be encouraged in patients evaluated more than four weeks preoperatively (grade B).

\section{Conclusion - hyper-reactive airway disease}

The patient presented in the case scenario had active respiratory symptoms less than 30 days ago and continues to smoke. Her risk of perioperative complications is increased. Preoperative spirometry is of little predictive value and need not be ordered. Smoking cessation for more than four weeks and delay of surgery for 30 days following resolution of respiratory symptoms should be considered to minimize her risk of perioperative respiratory complications.

\section{Coronary artery disease}

Scenario

A 68-yr-old male is scheduled to undergo a laparoscopic cholecystectomy on an outpatient basis. He has a history of uncomplicated acute MI nine weeks previously and is treated for hypertension (current blood pressure $150 / 90)$. He rarely experiences angina on exertion. He abandoned smoking three months ago, and is now on a regular exercise program. He can climb three flights of stairs without angina or dyspnea. Current medications include atenolol $25 \mathrm{mg}$ po daily and low-dose aspirin.

\section{Discussion}

The most recent American College of Cardiology/American Heart Association guideline (ACC/AHA) update on perioperative evaluation for noncardiac surgery ranks endoscopic surgery in the "low risk" ( $<1 \%$ cardiac events) category for noncardiac surgical procedures. ${ }^{21}$ The risks of laparoscopic cholecystectomy are primarily due to traumatic injuries resulting from blind trocar insertion, and the physiologic changes associated with patient positioning and creation of a pneumoperitoneum. ${ }^{46}$ Acute increases in mean arterial pressure are associated with insufflation of $\mathrm{CO}_{2}$ and increased concentrations of renin and aldosterone. ${ }^{47}$ 


\section{Is this patient at risk for perioperative cardiovascular events?}

There is limited information addressing the risk of perioperative cardiac events associated with ambulatory anesthesia per se. One previous study demonstrated that hypertension, arrhythmias, diabetes and smoking are predictors for perioperative adverse events in day surgery patients. ${ }^{38}$ However, the sample size of this four-centre study was too small to allow the validation of these predictors. Among a cohort of over 17,000 day surgery patients, those with congestive heart failure demonstrated the highest frequency of intraoperative events, followed by patients with hypertension. Seven discrete associations between pre-existing medical conditions and perioperative adverse events were identified, with hypertension doubling the occurrence of any intraoperative event, as well as postoperative cardiovascular events. ${ }^{9}$ The overwhelming majority of cardiovascular events were hemodynamic abnormalities such as hypertension and arrhythmia. No deaths or cardiac arrests were noted and only a single MI was reported. No association was identified between CAD and outcome. However, the prevalence of angina $(4.3 \%)$ and past MI $(2.5 \%)$ in the cohort may have been insufficient to demonstrate an effect. A larger prospective study of more than 38,000 ASA I to III surgical day care patients found that only 33 patients (1:1366) experienced major morbidity or mortality. Fourteen of these patients experienced a MI within two weeks of their operation (overall rate 1:3220), and two of these patients died. ${ }^{2}$ Ambulatory surgery is infrequently associated with major adverse cardiac events, however hemodynamic changes are more frequent in patients with hypertension (grade B).

\section{In view of his relatively recent $M I$, should surgery be delayed?}

Studies dating back to the early 1970's show that the risk of myocardial re-infarction following noncardiac surgery is increased when the operation occurs within six months of a MI with the first three months representing the period of greatest risk. ${ }^{48,49}$ With the possible exception of patients undergoing major vascular surgery, ${ }^{50}$ these historical time intervals are gradually being re-defined. In the current cardiac era, risk stratification strategies, thrombolytic therapy, and coronary angioplasty all have an important impact on the manner in which these patients are viewed. To date there is no evidence quantifying the influences of these changes in MI care on perioperative outcome. It would be prudent to delay surgery until any atherosclerotic plaque stabilizes and the myocardium heals, which usually requires six to eight weeks. Current management of MI reflect- ed in the recent ACC/AHA guidelines ${ }^{21}$ suggests that elective surgery may proceed safely in as little as six weeks following MI (grade D).

Is preoperative non-invasive cardiac testing indicated? Guidelines for cardiac testing have been published elsewhere. ${ }^{51-53}$ The patient's modified cardiac risk index score ${ }^{54}$ (Table II) is in the class I category (0-15 points). The presence of two low-risk variables from the indices of Eagle ${ }^{55}$ and Vanzetto ${ }^{56}$ (Table III) place the patient at an intermediate $(3-15 \%)$ risk of cardiac events. This patient reports that he is capable of greater than five metabolic equivalents (METS) of exertion. Good functional capacity places him at a lower risk than those incapable of five METS, whose risk of perioperative mortality is significant $(\mathrm{OR}=9.7$; 95\% CI 2.5-37). ${ }^{57}$ In the absence of either stressinduced myocardial ischemia, significant ventricular or valvular dysfunction, or alteration of medical therapy preoperative testing is not indicated. Patients at intermediate cardiac risk who are not undergoing high-risk surgery require no further testing, and may proceed directly to surgery (grade B).

\section{Is prolonged cardiovascular monitoring indicated?}

Pneumoperitoneum reduces cardiac output and renal blood flow. While such changes are well tolerated in most patients, the changes in cardiac patients are quantitatively more significant, and may be clinically important. Decreases in mixed venous oxygen saturation were identified in $50 \%$ of ASA III to IV patients during laparoscopy, despite preoperative optimization of their condition using a pulmonary artery catheter. ${ }^{58} \mathrm{~A}$ variety of pharmacologic approaches have been investigated to manage the hemodynamic changes induced by abdominal insufflation in select patients with heart disease, ${ }^{59}$ although no study has shown an overall effect on perioperative cardiac outcomes in at-risk patients. As hemodynamic changes resolve within an hour in most patients $^{60}$ the physiologic changes secondary to the pneumoperitoneum do not warrant admission or prolonged stay in this patient with stable CAD (grade D).

\section{Conclusions - CAD}

This somewhat older patient with stable coronary disease and good ventricular function may proceed with the scheduled outpatient laparoscopic cholecystectomy. It is imperative that his $ß$-blocker be continued throughout the perioperative period. The general anesthetic regimen should take into consideration the hemodynamic effects of the pneumoperitonum, balancing determinants of myocardial oxygen supply and demand, ST segment monitoring, and promptly treat- 
TABLE II Modified cardiac risk index ${ }^{54}$

\begin{tabular}{|c|c|}
\hline Variable & Points \\
\hline \multicolumn{2}{|l|}{ Coronary artery disease } \\
\hline Myocardial infarction $<$ six months earlier & 10 \\
\hline Myocardial infarction $>$ six months earlier & 5 \\
\hline \multicolumn{2}{|l|}{ Canadian Cardiovascular Society angina classification } \\
\hline Class III & 10 \\
\hline Class IV & 20 \\
\hline \multicolumn{2}{|l|}{ Alveolar pulmonary edema } \\
\hline Within one week & 10 \\
\hline Ever & 5 \\
\hline Suspect critical aortic stenosis & 20 \\
\hline \multicolumn{2}{|l|}{ Arrythmias } \\
\hline Rhythm other than sinus or sinus and premature atrial contractions & 5 \\
\hline$>$ five premature ventricular contractions & 5 \\
\hline \multirow{2}{*}{\multicolumn{2}{|c|}{$\begin{array}{l}\text { Poor general medical status defined as any of the following: } \\
\qquad \begin{array}{l}\mathrm{PO}_{2}<60 \mathrm{mmHg}, \mathrm{PCO}_{2}>50 \mathrm{mmHg}, \mathrm{K}+<3 \mathrm{mmol} \cdot \mathrm{L}^{-1} \text {, } \\
\mathrm{BUN}>50 \mathrm{mmol} \cdot \mathrm{L}^{-1}, \mathrm{Cr}>260 \mu \mathrm{mol} \cdot \mathrm{L}^{-1} \text {, bedridden }\end{array}\end{array}$}} \\
\hline & \\
\hline Age $>70 \mathrm{yr}$ & 5 \\
\hline Emergency surgery & 10 \\
\hline
\end{tabular}

Class $\mathrm{I}=0$ to 15 points, class $\mathrm{II}=20$ to 30 points; class $3=$ more than 30 points. Canadian Cardiovascular Society classification of angina: $0=$ asymptomatic; $\mathrm{I}=$ angina with strenuous exercise; $\mathrm{II}=$ angina with moderate exertion; $\mathrm{III}=$ angina with walking 1 to 2 level blocks or climbing one flight of stairs or less at a normal pace; IV = inability to perform any physical activity without development of angina. BUN = blood urea nitrogen; $\mathrm{Cr}=$ creatinine.

TABLE III Factors predicting perioperative cardiac morbidity - low risk variables

\begin{tabular}{ll}
\hline Criteria of Eagle et al. ${ }^{55}$ & Criteria of Vanzetto et al. ${ }^{56}$ \\
\hline Age $>70 \mathrm{yr}$ & Age $>70 \mathrm{yr}$ \\
History of angina & History of angina \\
Diabetes mellitus & Diabetes mellitus \\
Q waves on electrocardiogram & Q waves on electrocardiogram \\
History of ventricular ectopy & History of myocardial infarction \\
& ST-segment ischemic abnormalities during resting electrocardiography \\
& Hypertension with severe left ventricular hypertrophy \\
\hline
\end{tabular}

ing ischemic events should they occur. There is no evidence that routine admission and monitoring of a patient with this cardiac risk profile would further improve his overall perioperative cardiac outcome.

\section{Obstructive sleep apnea (OSA) \\ Scenario}

A 55-yr-old obese male is scheduled for an outpatient knee arthroscopy. He recently underwent a sleep study, which revealed severe OSA and nasal continuous positive airway pressure (nCPAP) was prescribed. $\mathrm{He}$ wears the device inconsistently because he finds the mask uncomfortable.

\section{Discussion}

It is estimated that $4 \%$ of male and $2 \%$ of female middle-aged adults have clinically significant symptoms of OSA. ${ }^{61,62}$ Despite increasing recognition, at least $80 \%$ of patients with OSA are undiagnosed and the incidence of presumed or diagnosed OSA is expected to increase five to tenfold over the next decade. ${ }^{63}$ Patients with OSA pose several challenges to the anesthesiologist and it is essential to identify and treat these patients preoperatively. ${ }^{64}$

During sleep, there is a reduction in tone of the upper airway muscles leading to a narrowing of the airway and turbulent airflow. ${ }^{65}$ Patients with OSA experience repeated episodes of hypoventilation, desaturation, sympathetic arousal and awakening, leading to fragmented sleep. The severity of OSA is determined by the apnea hypopnea index which is the number of apneas or hypopneas per hour of sleep (mild 5-15, moderate 15-30, severe > 30). ${ }^{62,66}$ The characteristic signs and symptoms of OSA syndrome are listed in Table IV. ${ }^{66}$ 
TABLE IV Symptoms and signs of obstructive sleep apnea

\begin{tabular}{ll}
\hline Symptoms & Signs \\
\hline Heavy snoring & Central obesity \\
Witnessed apneas & Increased neck circumference \\
Excessive daytime somnolence & Edematous soft palate or uvula \\
Morning headaches & Retrognathia \\
Poor memory/concentration & Arterial hypertension \\
Accidents related to sleepiness & Pulmonary hypertension \\
Nocturia & Cardiac dysrhythmia \\
\hline
\end{tabular}

Are adult patients with OSA at an increased risk for perioperative complications?

OSA patients are more likely to be difficult to intubate and emergency airway equipment should be readily available. ${ }^{67} \mathrm{~A}$ recent retrospective study found $22 \%$ of OSA patients were difficult to intubate. ${ }^{68}$ Several factors, including obesity, retrognathia and increased neck circumference contribute to the increased difficulty with intubation. ${ }^{61}$ Hiremath et al. suggest that patients known or suspected to be difficult to intubate should be screened for signs and symptoms of OSA. ${ }^{69}$ Recovery room complications are also more frequent and $\mathrm{m}^{\mathrm{a}} \mathrm{y}$ include hypertension, dysrhythmia, desaturation, airway obstruction, or reintubation. ${ }^{64}$ Sedative and opioid medications may exacerbate sleep-related apneic episodes especially in untreated patients. ${ }^{70}$ Judicious use of these agents is recommended. A casecontrol study of hip or knee replacement surgery found $24 \%$ of OSA patients (vs $9 \%$ control) had serious complications postoperatively and a longer length of hospital stay. ${ }^{64}$ There are several case reports of patients with OSA dying suddenly on the ward following general anesthesia. ${ }^{70-72}$ In most cases, the diagnosis of OSA was unknown or unrecognized at the time of surgery. A recent article describes eight cases of "unexplained" postoperative cardiopulmonary arrests in hospitalized patients. All patients had received parenteral narcotics and, eventually all were diagnosed with OSA. ${ }^{70} \mathrm{~A}$ search of the ASA Closed Claims Project database of 5,480 claims identified 19 claims involving sleep apnea patients. ${ }^{\mathrm{A}}$ Eighteen of these 19 patients sustained death or brain damage related to adverse respiratory system events. Patients with OSA are at increased risk of perioperative complications (grade C).

Do effectively treated OSA patients have a lower risk of perioperative complications compared to untreated patients?

Nasally applied CPAP is the treatment of choice for clinically significant OSA. ${ }^{62,65}$ Effective use of nCPAP may improve symptoms of right heart failure dramatically and improve blood pressure over time. Rennotte reports two cases of major postoperative complications in patients with untreated OSA; these reports are followed by a series of 14 consecutive patients undergoing similar surgery who were effectively treated with nCPAP for up to three weeks before surgery and postoperatively. ${ }^{72}$ No major complications were noted in those treated with nCPAP despite the use of opioid analgesics. Another study found OSA patients receiving prophylactic nCPAP did not develop any complications on the first postoperative evening. ${ }^{64}$ None of the cases of sudden death or cardiorespiratory arrests were in patients reported to be wearing nCPAP. Although there is no literature to recommend the optimum duration of treatment prior to elective surgery, patients should be proficient in applying the device themselves and OSA symptoms should be improved. ${ }^{62}$ It is essential for anesthesiologists to identify patients likely to have OSA during the preoperative assessment. ${ }^{62,66,70}$ Patients who are symptomatic despite diagnosis and treatment and those with suspected OSA should be referred for a polysomnographic study and optimization prior to elective surgery. ${ }^{73}$ Untreated or inadequately treated OSA is associated with a higher incidence of perioperative complications (grade C).

\section{Does the severity of OSA influence the perioperative management?}

There are no studies that examine the effect of severity of OSA on the risk of complications. Siyam et al. were unable to show a relationship between severity of OSA and the occurrence of difficult intubation. ${ }^{68} \mathrm{~A}$ retrospective study of patients undergoing total joint arthroplasty showed no clear relationship between severity of OSA and perioperative outcome. ${ }^{64}$ However, most authors feel that it is reasonable to consider the severity of OSA when formulating a management plan (grade D).

\section{Does the type of anesthetic influence postoperative man- agement?}

Although there are no data to support the preferential use of regional over general anesthesia, regional anesthesia may limit the interactions between sleep apnea and sedative agents and circumvent difficulties with airway management. ${ }^{62,66,67}$ The type of surgery and need for postoperative narcotic analgesics are probably more important than the choice of anesthetic (grade D).

A Posner KL. Project Manager. ASA Closed Claims Database. Personal communication. 2003. 
Postoperative management must always include the use of nCPAP.

\section{Should OSA patients be admitted to hospital postopera- tively?}

Outpatient surgery for patients with OSA remains controversial. A recent retrospective study compared 234 OSA patients with controls matched for age, sex, body mass index, and procedure. Unanticipated admission rates or adverse events were similar between groups. ${ }^{74}$ However, patients in the control group did not have a sleep study or screening questionnaire to rule out OSA and the $24 \%$ overall rate of unanticipated admissions is well above that expected for outpatient surgery. Furthermore, no outcome data were presented from those patients discharged from the hospital. The literature neither confirms nor refutes the safety of ambulatory surgery in OSA patients. Expert opinion is that well-treated OSA patients having low risk procedures preformed under local or regional anesthesia with little or no sedation and minimal need for narcotic-based analgesics can be discharged after surgery. ${ }^{61,62,73}$ A majority of Canadian anesthesiologists surveyed would discharge OSA patients after local or regional anesthesia unless postoperative narcotics were required ${ }^{75}$ (grade D).

\section{Conclusion - OSA}

A patient with diagnosed OSA undergoing arthroscopic surgery may be considered for ambulatory surgery. Patients should wear their nCPAP postoperatively for all sleep periods. Pain should be managed with non-narcotic analgesics and opioid drugs should be avoided. A single retrospective study demonstrates that patients with OSA undergoing ambulatory surgery under general anesthesia were not at an increased risk of adverse postoperative events. Until better evidence is available many anesthesiologists may still prefer to proceed under regional anesthesia.

Part II of this review will focus on ambulatory anesthesia care for patients with the following considerations: diabetes, morbid obesity, the ex-premature infant, the child with an upper respiratory infection, malignant hyperthermia, and concurrent use of monoamine oxidase inhibitors.

\section{Acknowledgements}

The Canadian Ambulatory Anesthesia Research and Education (CAARE) Group would like to thank Dr. Ramiro Arellano, Dr. Peter Duncan, Dr. Angela Fitzmaurice, Dr. Ken LeDez, Dr. Stuart McCluskey, Dr. Barbara Pask, Dr. Donald Wilson, and Dr. Suntheralingam Yogendran for their participation. Special thanks to Alexandra Davis for her assistance with the literature searches and Dr. Masao Yamashita for translation services.

\section{APPENDIX I MEDLINE search strategy}

\author{
Ambulatory outcomes search \\ $1 \quad \exp$ anesthesia.MeSH \\ 2 (anesthe\$ or anaesthe\$).tw. \\ 3 anesthesiology.MeSH \\ 4 or $/ 1-3$ \\ 5 exp postoperative complications.MeSH \\ 6 (postoperative adj2 complication\$).tw. \\ 7 (post-operative adj2 complication\$).tw. \\ 8 co.fs. \\ 9 patient readmission.MeSH \\ 10 (readmission or readmit\$).tw. \\ 11 complication? follow\$ surgery.tw. \\ 12 complication? after surgery.tw. \\ 13 or $/ 5-12$ \\ 14 ambulatory surgical procedures.MeSH \\ 15 (day adjl surger\$).tw. \\ 16 (ambulatory adjl surger\$).tw. \\ 17 (office adjl surger\$).tw. \\ 18 (outpatient adjl surger\$).tw. \\ 19 or/14-18 \\ 20 and 13
}

\section{Disease-specific search strategies}

1 Aged.MeSH; aged, 80 and over.MeSH; frail elderly.MeSH;

2 Heart transplantation.MeSH; heart transplant\$.tw; cardiac transplant\$.tw.

3 Asthma.MeSH; asthma.tw;

4 Myocardial infarction.MeSH; myocardial infarct\$.tw.

$5 \quad$ Sleep apnea syndromes.MeSH; sleep-disordered breathing.tw; (sleep apnea or sleep apnoea).tw.

6 Diabetes mellitus, insulin-dependent.MeSH; iddm.tw; insulin dependent.tw; (type 1 and diabetes).mp. ( $\mathrm{mp}=$ title, abstract, cas registry/ec number word, mesh subject heading)

7 Obesity, morbid.MeSH; (morbid\$ adjl obes\$).tw;

8 Infant, premature.MeSH; ex-premature.tw; former preterm.tw; former premature.tw.

9 Respiratory tract infections.MeSH; urti.tw; upper respiratory tract infection $\$$.tw.

10 Malignant hyperthermia.MeSH; malignant hyperthermia.tw; malignant hyperpyrexia.tw.

11 exp monoamine oxidase inhibitors.MeSH; mao inhibitor\$.tw; reversible inhibitor\$ monoamine oxidase.tw; maoi.tw. 


\section{APPENDIX II CEBM levels of evidence}

When Appraising an Article About...

\section{Level Therapy or Harm}

la Systematic review of RCTs (with homogeneity)

lb Individual RCT (with narrow confidence intervals)

lc All or none study

2a Systematic review of cohort studies (with homogeneity)

$2 b \quad$ Individual cohort study Poor quality RCT

2c Outcomes Research

Ecological survey

3a Systematic review of case-control studies

(with homogeneity)

3b Individual case-control study

4 Case-series

Poor quality cohort study

Poor quality case-control study

$5 \quad$ Expert opinion without explicit critical appraisal, or based on physiology, bench research or "first principles"

\section{Prognosis}

Systematic review (with homogeneity) of inception cohort studies

Clinical decision rule validated in different populations

) Individual inception cohort study with $>80 \%$ follow-up

Clinical decision rule validated in a single population

All or none case-series

Systematic review (with homogeneity) of

either: retrospective cohort studies or untreated control groups in RCTs

Retrospective cohort study

Follow-up of untreated control patients in an individual RCT;

Derivation of clinical decision rule or validated

on split-sample only

Outcomes Research

Case-series Poor quality prognostic cohort study

Expert opinion without explicit critical appraisal, or based on physiology, bench research or

"first principles"

$\mathrm{CEBM}=$ centre for evidence based medicine; $\mathrm{RCT}=$ randomized controlled trial; Case-control studies for prognosis should be considered poor quality prognostic cohorts or case series (Level 4). Personal communication with Dr. Bob Phillips. Adapted from Oxford-Center for Evidence Based Medicine. Levels of Evidence and Grades of Recommendation. http://www.cebm.net/levels_of_evidence.asp\#notes.

\section{APPENDIX III Grades of recommendation}

A Consistent level 1 studies

B Consistent level 2 or 3 studies

Extrapolations from level 1 studies

C Level 4 studies

Extrapolations from level 2 or 3 studies

D Level 5 evidence

Troublingly inconsistent or inconclusive studies of any level

Extrapolations = data used in a situation with clinically important differences from original study population. Adapted from Oxford-Center for Evidence Based Medicine. Levels of evidence and grades of recommendation. http://www.cebm.net/levels_of_evidence.asp\#notes. 


\section{References}

1 Canadian Institute for Health Information. Health Services - Hospital Discharges. Day procedures by province of facility location. Canadian Institute for Health Information 2003: 10-25.

2 Warner MA, Shields SE, Chute CG. Major morbidity and mortality within 1 month of ambulatory surgery and anesthesia. JAMA 1993; 270: 1437-41.

3 Phillips B, Ball C, Sackett D, Badenoch D, Strauss S, Haynes $B$, et al. Levels of evidence and grades of recommendation. Centre for Evidence Based Medicine. 2000; available from URL; http://www.cebm.net/levels_of_evidence.asp.

4 Fortier J, Chung F, Su J. Unanticipated admission after ambulatory surgery - a prospective study. Can J Anaesth 1998; 45: 612-9.

5 Leung JM, Dzankic S. Relative importance of preoperative health status versus intraoperative factors in predicting postoperative adverse outcomes in geriatric surgical patients. J Am Geriatr Soc 2001; 49: 1080-5.

6 Chung F, Mezei G, Tong D. Adverse events in ambulatory surgery. A comparison between elderly and younger patients. Can J Anesth 1999; 46: 309-21.

7 Fleisher LA, Pasternak R, Lyles A. A novel index of elevated risk for hospital admission or death immediately following outpatient surgery. Anesthesiology 2002; 96: A38 (abstract).

8 Chung F, Mezei G. Adverse outcomes in ambulatory anesthesia. Can J Anesth 1999; 46(5 Pt 2): R18-34.

9 Chung F, Mezei G, Tong D. Pre-existing medical conditions as predictors of adverse events in day-case surgery. Br J Anaesth 1999; 83: 262-70.

10 Mezei G, Chung F. Return hospital visits and hospital readmissions after ambulatory surgery. Ann Surg 1999; 230: 721-7.

11 Dzankic S, Pastor D, Gonzalez C, Leung JM. The prevalence and predictive value of abnormal preoperative laboratory tests in elderly surgical patients. Anesth Analg 2001; 93: 301-8.

12 Schein OD, Katz J, Bass EB, et al. The value of routine preoperative medical testing before cataract surgery. Study of Medical Testing for Cataract Surgery. N Engl J Med 2000; 342: 168-75.

13 Organ Procurement and Transplantation Network. Heart Kaplan-Meier patient survival rates for transplants performed: 1996-2001. 2003; available from URL; http://www.optn.org/latestData/rptStrat.asp.

14 Vega KJ, Pina I, Krevsky B. Heart transplantation is associated with an increased risk for pancreaticobiliary disease. Ann Intern Med 1996; 124: 980-3.

15 Miniati DN, Robbins RC. Heart transplantation: a thirty-year perspective. Annu Rev Med 2002; 53: 189-205.
16 Kostopanagiotou G, Smyrniotis V, Arkadopoulos N, Theodoraki K, Papadimitriou L, Papadimitriou J. Anesthetic and perioperative management of adult transplant recipients in nontransplant surgery. Anesth Analg 1999; 89: 613-22.

17 Labarrere CA, Nelson DR, Cox CJ, Pitts D, Kirlin P, Halbrook $H$. Cardiac-specific troponin I levels and risk of coronary artery disease and graft failure following heart transplantation. JAMA 2000; 284: 457-64.

18 Mullen JC, Bentley MJ, Scherr KD, et al. Troponin T and I are not reliable markers of cardiac transplant rejection. Eur J Cardiothorac Surg 2002; 22: 233-7.

19 Sharples LD, Jackson CH, Parameshwar J, Wallwork J, Large SR. Diagnostic accuracy of coronary angiography and risk factors for post-heart-transplant cardiac allograft vasculopathy. Transplantation 2003; 76 : 679-82.

20 Derumeaux $G$, Redonnet $M$, Soyer $R$, Cribier A, Letac $B$. Assessment of the progression of cardiac allograft vasculopathy by dobutamine stress echocardiography. J Heart Lung Transplant 1998; 17: 259-67.

21 Eagle KA, Berger PB, Calkins H, et al. ACC/AHA guideline update on perioperative cardiovascular evaluation for noncardiac surgery. A report of the American College of Cardiology/American Heart Association Task Force on Practice Guidelines (Committee to Update the 1996 Guidelines on Perioperative Cardiovascular Evaluation for Noncardiac Surgery). 2002; available from URL; http://www.americanheart.org/downloadable/heart/1013454973885perio _update.pdf.

22 English RF, Pophal SA, Bacanu SA, et al. Long-term comparison of tacrolimus- and cyclosporine-induced nephrotoxicity in pediatric heart-transplant recipients. Am J Transplant 2002; 2: 769-73.

23 Ishani A, Erturk S, Hertz MI, Matas AJ, Savik K, Rosenberg $M E$. Predictors of renal function following lung or heart-lung transplantation. Kidney Int 2002; 61: 2228-34.

24 van Gelder T, Balk AH, Zietse R, Hesse C, Mochtar B, Weimar $W$. Renal insufficiency after heart transplantation: a case-control study. Nephrol Dial Transplant 1998; 13: 2322-6.

25 Backman SB, Fox GS, Stein RD, Ralley FE. Neostigmine decreases heart rate in heart transplant patients. Can J Anaesth 1996; 43: 373-8.

26 Murphy DA, Thompson GW, Ardell JL, et al. The heart reinnervates after transplantation. Ann Thorac Surg 2000; 69: 1769-81.

27 Joshi GP, Hein HA, Ramsay MA, Foreman ML. Hemodynamic response to anesthesia and pneumoperitoneum in orthotopic cardiac transplant recipients. Anesthesiology 1996; 85: 929-33. 
28 Cheng DC, Ong DD. Anaesthesia for non-cardiac surgery in heart-transplanted patients. Can J Anaesth 1993; 40: 981-6.

29 Richardson WS, Surowiec WJ, Carter KM, Howell TP, Mehra MR, Bowen JC. Gallstone disease in heart transplant recipients. Ann Surg 2003; 237: 273-6.

30 Menegaux F, Dovent R, Tabbi D, Pavie A, Chigot JP, Gandjbakhch $I$. Biliary surgery after heart transplantation. Am J Surg 1998; 175: 320-1.

31 Anonymous. Standards for the diagnosis and care of patients with chronic obstructive pulmonary disease. American Thoracic Society. Am J Respir Crit Care Med 1995; 152(5 Pt 2): S77-121.

32 Dosman JA, Gomez SR, Zhou C. Relationship between airways responsiveness and the development of chronic obstructive pulmonary disease. Med Clin North Am 1990; 74: 561-9.

33 Arozullah AM, Khuri SF, Henderson WG, Daley J. Development and validation of a multifactorial risk index for predicting postoperative pneumonia after major noncardiac surgery. Ann Intern Med 2001; 135: 847-57.

34 Wong DH, Weber EC, Schell MJ, Wong AB, Anderson CT, Barker SJ. Factors associated with postoperative pulmonary complications in patients with severe chronic obstructive pulmonary disease. Anesth Analg 1995; 80: $276-84$.

35 Warner DO, Warner MA, Barnes RD, et al.

Perioperative respiratory complications in patients with asthma. Anesthesiology 1996; 85: 460-7.

36 Kumeta $\Upsilon$, Hattori A, Mimura M, Kishikawa K, Namiki A. A survey of perioperative bronchospasm in 105 patients with reactive airway disease (Japanese). Masui 1995; 44: 396-401.

37 Chung F, Mezei G. Factors contributing to a prolonged stay after ambulatory surgery. Anesth Analg 1999; 89: 1352-9.

38 Duncan PG, Cohen MM, Tweed WA, et al. The Canadian four-centre study of anaesthetic outcomes: III. Are anaesthetic complications predictable in day surgical practice? Can J Anaesth 1992; 39(5 Pt 1): 440-8.

39 Warner DO, Warner MA, Offord KP, Schroeder DR, Maxson P, Scanlon PD. Airway obstruction and perioperative complications in smokers undergoing abdominal surgery. Anesthesiology 1999; 90: 372-9.

40 Wittgen CM, Naunheim KS, Andrus CH, Kaminski $D L$. Preoperative pulmonary function evaluation for laparoscopic cholecystectomy. Arch Surg 1993; 128: 880-6.

41 Mitchell CK, Smoger SH, Pfeifer MP, et al. Multivariate analysis of factors associated with postoperative pulmonary complications following general elective surgery. Arch Surg 1998; 133: 194-8.

42 Kroenke K, Lawrence VA, Theroux JF, Tuley MR. Operative risk in patients with severe obstructive pulmonary disease. Arch Intern Med 1992; 152: 967-71.

43 Lawrence VA, Page CP, Harris GD. Preoperative spirometry before abdominal operations. A critical appraisal of its predictive value. Arch Intern Med 1989; 149: 280-5.

44 Myles PS, Iacono GA, Hunt JO, et al. Risk of respiratory complications and wound infection in patients undergoing ambulatory surgery. Smokers versus nonsmokers. Anesthesiology 2002; 97: 842-7.

45 Moller AM, Villebro N, Pedersen T, Tonnesen H. Effect of preoperative smoking intervention on postoperative complications: a randomised clinical trial. Lancet 2002; 359: 114-7.

46 Cunningham AJ, Brull SJ. Laparoscopic cholecystectomy: anesthetic implications. Anesth Analg 1993; 76 : $1120-33$.

47 O'Leary E, Hubbard K, Tormey W, Cunningham AJ. Laparoscopic cholecystectomy: haemodynamic and neuroendocrine responses after pneumoperitoneum and changes in position. Br J Anaesth 1996; 76: 640-4.

48 Tarban S, Moffitt EA, Taylor WF, Giuliani ER. Myocardial infarction after general anesthesia. JAMA 1972; 220: 1451-4.

49 Rao TL, Jacobs KH, El-Etr AA. Reinfarction following anesthesia in patients with myocardial infarction. Anesthesiology 1983; 59: 499-505.

50 Shah KB, Kleinman BS, Sami H, Patel J, Rao TL. Reevaluation of perioperative myocardial infarction in patients with prior myocardial infarction undergoing noncardiac operations. Anesth Analg 1990; 71: 231-5.

51 Fleisher LA, Eagle KA. Clinical practice. Lowering cardiac risk in noncardiac surgery. N Engl J Med 2001; 345: 1677-82.

52 Anonymous. Guidelines for assessing and managing the perioperative risk from coronary aretery disease associated with major noncardiac sugery. American College of Physicians. Ann Intern Med 1997; 127: 309-12.

53 Palda VA, Detsky AS. Perioperative assessment and management of risk from coronary artery disease. Ann Intern Med 1997; 127: 313-28.

54 Detsky AS, Abrams HB, McLaughlin JR, et al. Predicting cardiac complications in patients undergoing non-cardiac surgery. J Gen Intern Med 1986; 1: 211-9.

55 Eagle KA, Coley CM, Newell JB, et al. Combining clini$\mathrm{cal}$ and thallium data optimizes preoperative assessment of cardiac risk before major vascular surgery. Ann Intern Med 1989; 110: 859-66.

56 Vanzetto G, Machecourt J, Blendea D, et al. Additive 
value of thallium single-photon emission computed tomography myocardial imaging for prediction of perioperative events in clinically selected high cardiac risk patients having abdominal aortic surgery. Am J Cardiol 1996; 77: 143-8.

57 Browner WS, Li J, Mangano DT. In-hospital and longterm mortality in male veterans following noncardiac surgery. The Study of Perioperative Ischemia Research Group. JAMA 1992; 268: 228-32.

58 Safran D, Sgambati S, Orlando R III. Laparoscopy in high-risk cardiac patients. Surg Gynecol Obstet 1993; 176: 548-54.

59 Feig BW, Berger DH, Dougherty TB, et al. Pharmacologic intervention can reestablish baseline hemodynamic parameters during laparoscopy. Surgery 1994; 116: 733-9.

60 Harris SN, Ballantyne GH, Luther MA, Perrino AC Jr. Alterations of cardiovascular performance during laparoscopic colectomy: a combined hemodynamic and echocardiographic analysis. Anesth Analg 1996; 83: 482-7.

61 Benumof JL. Obstructive sleep apnea in the adult obese patient: implications for airway management. J Clin Anesth 2001; 13: 144-56.

62 Tung A, Rock P. Perioperative concerns in sleep apnea. Curr Opin Anaesthesiol 2001; 14: 671-8.

63 Young T, Evans L, Finn L, Palta M. Estimation of the clinically diagnosed proportion of sleep apnea syndrome in middle-aged men and women. Sleep 1997; 20: 705-6.

64 Gupta RM, Parvizi J, Hanssen AD, Gay PC. Postoperative complications in patients with obstructive sleep apnea syndrome undergoing hip or knee replacement: a case-control study. Mayo Clin Proc 2001; 76: 897-905.

65 Strollo PJ Jr, Rogers RM. Obstructive sleep apnea. N Engl J Med 1996; 334: 99-104.

66 Loadsman JA, Hillman DR. Anaesthesia and sleep apnoea. Br J Anaesth 2001; 86: 254-66.

67 Chung F, Imarengiaye C. Management of sleep apnea in adults. Can J Anesth 2002; 49: Rl-6.

68 Siyam MA, Benhamou D. Difficult endotracheal intubation in patients with sleep apnea syndrome. Anesth Analg 2002; 95: 1098-102.

69 Hiremath AS, Hillman DR, James AL, Noffsinger WJ, Platt PR, Singer SL. Relationship between difficult tracheal intubation and obstructive sleep apnoea. $\mathrm{Br} \mathrm{J}$ Anaesth 1998; 80: 606-11.

70 Lofsky $A$. Sleep apnea and narcotic postoperative pain medication: a morbidity and mortality risk. Anesthesia Patient Safety Foudation Newsletter 2002; 17: 24-5.

71 Cullen DJ. Obstructive sleep apnea and postoperative analgesia-a potentially dangerous combination
(Editorial). J Clin Anesth 2001; 13: 83-5.

72 Rennotte MT, Baele P, Aubert G, Rodenstein DO. Nasal continuous positive airway pressure in the perioperative management of patients with obstructive sleep apnea submitted to surgery. Chest 1995; 107: 367-74.

73 Deutscher R, Bell D, Sharma S. OSA protocol promotes safer care. Anesthesia Patient Safety Foundation Newsletter 2002; 17: 58.

74 Sabers C, Plevak DJ, Schroeder DR, Warner DO. The diagnosis of obstructive sleep apnea as a risk factor for unanticipated admissions in outpatient surgery. Anesth Analg 2003; 96: 1328-35.

75 Friedman Z, Wong DT, Chung F. What are the ambulatory surgical patient selection criteria in Canada? Can J Anesth 2003; 50(Suppl): Al6 (abstract). 